\title{
Focus takes time: structural effects on reading
}

\author{
Matthew W. Lowder ${ }^{1}$ Peter C. Gordon ${ }^{2}$
}

Published online: 12 May 2015

(C) Psychonomic Society, Inc. 2015

\begin{abstract}
Previous eye-tracking work has yielded inconsistent evidence regarding whether readers spend more or less time encoding focused information compared with information that is not focused. We report the results of an eyetracking experiment that used syntactic structure to manipulate whether a target word was linguistically defocused, neutral, or focused, while controlling for possible oculomotor differences across conditions. As the structure of the sentence made the target word increasingly more focused, reading times systematically increased. We propose that the longer reading times for linguistically focused words reflect deeper encoding, which explains previous findings showing that readers have better subsequent memory for focused versus defocused information.
\end{abstract}

Keywords Linguistic focus · Eye-tracking $\cdot$ Syntax $\cdot$ Clefts · Pseudoclefts

Due to the inherent limitations of human cognition, efficient processing depends on the use of environmental cues to allocate resources to stimuli or characteristics of stimuli that are important to the task at hand. In the domain of language comprehension, sentences contain multiple cues that readers or listeners may use to identify the focus of the sentence- or the linguistic material that is signaled as most important or prominent (Halliday, 1967), in contrast to information that is

Matthew W. Lowder

mlowder@ucdavis.edu

1 Department of Psychology, University of California, Davis, Young Hall, One Shields Avenue, Davis, CA 95616, USA

2 Department of Psychology, University of North Carolina at Chapel Hill, Chapel Hill, NC, USA presented as background. Linguistic focus may be signaled via prosody (e.g., John kissed MARY), focus particles (e.g., John kissed only Mary), prior discourse context (e.g., Who did John kiss? John kissed Mary), or syntactic structure (e.g., The girl who John kissed was Mary). In each of these examples, the fact that John kissed someone is presented as presupposed background knowledge relative to the newly asserted, focused piece of information that Mary is the one that he kissed.

Previous work has demonstrated that linguistic focus has clear consequences in several domains of cognition. For example, compared to nonfocused information, linguistically focused information attracts attention more effectively (Cutler \& Fodor, 1979; Hornby, 1974; Langford \& Holmes, 1979; Sturt, Sanford, Stewart, \& Dawydiak, 2004), is remembered better (Birch \& Garnsey, 1995; Gernsbacher \& Jescheniak, 1995; McKoon, Ratcliff, Ward, \& Sproat, 1993; Singer, 1976) and leads to more accurate detection of false information (Baker \& Wagner, 1987; Bredart \& Modolo, 1988). Linguistic focus also facilitates inference drawing (Gergely, 1992), increases performance in a letter-detection task (Moravcsik \& Healy, 1998), and increases the likelihood that the focused word will be referred to again in a sentence-continuation task (Birch, Albrecht, \& Myers, 2000). Finally, several studies have demonstrated that the speed and accuracy of resolving anaphors depends critically on linguistic focus (Almor, 1999; Carpenter \& Just, 1977; Foraker \& McElree, 2007; Gordon \& Hendrick, 1997, 1998; Gordon \& Scearce, 1995; Klin, Weingartner, Guzman, \& Levine, 2004; McKoon, Ward, Ratcliff, \& Sproat, 1993).

Perhaps the most intuitive explanation for the cognitive advantages associated with linguistically focused information is that focus promotes deeper encoding. Eye-tracking experiments that have manipulated linguistic focus using a prior discourse context have tended to support this explanation (e.g., Benatar \& Clifton, 2014; Birch \& Rayner, 1997, 
Experiment 2; cf. Ward \& Sturt, 2007, who found no effect of focus, but who also confounded their focus manipulation with lexical repetition a few words before their target word). For example, Benatar and Clifton (Experiment 2) presented participants with passages like those in (1), where a target phrase (e.g., the doctor) was either given by a prior discourse context (1a) or was presented as new information (i.e., focused) (1b). Reading times were longer when target words were focused versus when they were given, reflecting the greater cost associated with integrating the target word into the reader's discourse representation in (1b) compared with (1a).

1a. Speaker A: Tell me, when did Caitlin leave to go to the cardiologist?

Speaker B: I believe she left to go to the doctor just a little while before 11 this morning.

1b. Speaker A: Tell me, when did Caitlin leave to go somewhere?

Speaker B: I believe she left to go to the doctor just a little while before 11 this morning.

In particular, Benatar and Clifton's work highlights the fact that linguistic focus can be manipulated in a variety of ways, and the authors note that different types of linguistic focus may be associated with different underlying mechanisms. While this may be true, their demonstration across three experiments that processing times are longer for focused versus nonfocused information is consistent with earlier work that showed similar eye-tracking patterns using very different manipulations of discourse context (e.g., Birch \& Rayner, 1997, Experiment 2).

In contrast to work that has manipulated focus via context, eye-tracking experiments that have used syntactic devices to manipulate linguistic focus have been largely inconclusive. Whereas some studies have shown that increases in linguistic focus are associated with increased reading times, consistent with the notion that linguistic focus promotes deeper encoding (e.g., Birch \& Rayner, 1997, Experiment 1; Price \& Sanford, 2012), other studies have shown that increases in linguistic focus are associated with decreased reading times, consistent with the notion that linguistic focus eases the cost of integrating a word with the sentence context (e.g., Birch \& Rayner, 2010; Morris \& Folk, 1998). The current work examines more closely the effects of syntactic focus during online sentence processing and identifies potential explanations for the previous inconsistencies in the literature.

Birch and Rayner (1997, Experiment 1) presented participants with sentences in which a target word (e.g., suburb) was either syntactically focused via a cleft construction, as in (2a), or nonfocused, as in (2b). Results showed a higher proportion of regressive saccades and longer rereading times on the target word in the focused compared to the nonfocused condition, supporting the notion that linguistically focused information is marked as important and promotes longer encoding times, which may explain why focused information is remembered better than nonfocused information.

2a. It was the suburb that received the most damage from the ice storm.

2b. Workers in the suburb hurried to restore power after the ice storm.

However, as noted by Birch and Rayner (2010), the target words in Birch and Rayner's (1997) nonfocused condition were actually syntactically defocused by virtue of appearing in an adjunct phrase, which made it difficult to isolate effects of focus from effects of defocus. Thus, Birch and Rayner (2010) presented participants with passages like those in (3), in which the syntactically focused target word (e.g., landlady) in (3a) was compared to a more neutral control condition, as in (3b). Results showed shorter first-pass and total reading times on the target word in the focused compared to the neutral condition, which was taken as evidence that linguistically focused information is more easily integrated into the reader's representation of the text than information presented in a more neutral context (see also Morris \& Folk, 1998).

3. The tenants at the complex were sick and tired of all the noise coming from \#204.

3a. It was the landlady who confronted the woman who lived there.

3b. The landlady confronted the woman who lived there.

Of particular note, Birch and Rayner (2010) argue for the importance of carefully assessing effects of linguistic focus and defocus relative to a neutral baseline, and they attribute the conflicting patterns in the literature at least in part to a failure to do so. Nonetheless, psycholinguistic research on the processing of linguistic focus has rarely systematically compared effects of focused, neutral, and defocused sentence contexts in a single experiment (cf. Price \& Sanford, 2012). Furthermore, previous studies that have manipulated sentence structure to investigate the effects of linguistic focus on reading times do not seem to have controlled adequately for possible oculomotor differences between conditions. For example, the target word in Birch and Rayner's (2010) focused condition (see 3a) always appeared further into the sentence than the target word in their neutral condition (see 3b). Because readers tend to make shorter fixations as they proceed through a sentence (e.g., Ferreira \& Henderson, 1993), the longer reading times for ( $3 \mathrm{~b}$ ) versus (3a) may reflect basic differences in reading speed rather than effects of focus. In addition, the words immediately before and immediately after the target word in Birch and Rayner (1997) and Birch 
and Rayner (2010) differed across conditions, which may have influenced eye movements as well. Thus, the goal of the current experiment was to determine how reading-time patterns on a target word differ as the structure of the sentence makes the word increasingly more focused while ensuring that any effects could not be explained on the basis of differences in oculomotor factors across conditions.

\section{Method}

\section{Participants}

Thirty-nine students at the University of North Carolina at Chapel Hill participated in this experiment in exchange for course credit. They were all native English speakers and had normal or corrected-to-normal vision.

\section{Materials}

Thirty-six sets of experimental sentences were constructed, as in (4). Three conditions were defined according to whether a target word (e.g., memo) was focused, neutral, or defocused. In the Focused condition (e.g., 4a), the target word was made syntactically prominent by virtue of a pseudocleft, whereas in the Defocused condition (e.g., 4c), the target word was syntactically deemphasized with a cleft that placed focus on a different region of the sentence. In the Neutral condition (4b), the target word was presented in a simple-sentence context. Across conditions, the target word was always preceded by the same two words (i.e., a determiner and a modifier). The material following the target noun was identical across conditions.

4a. What the secretary typed was the official memo about the new office policy. (Focused)

4b. Yesterday the secretary typed the official memo about the new office policy. (Neutral)

4c. It was the secretary that typed the official memo about the new office policy. (Defocused)

The number of words that preceded the target word differed across conditions (7 in the Focused condition, 7-9 in the Neutral condition depending on the length of the introductory phrase, and 8 in the Defocused condition); however, these differences in word position are smaller than those in some previous studies (e.g., Birch \& Rayner, 2010; see example 3 above). Furthermore, the sentences in the current experiment were presented to participants in Times New Roman font (a proportional font), which allowed the target words to appear in the same line position across conditions. We recorded the pixel position of the left edge of each target word across the three conditions (Focused $=694$, Neutral $=701$, Defocused $=$ 699) and found no significant differences between conditions.

The experimental sentences were counterbalanced across three lists so that each participant saw only one version of each item and so that each participant saw the same number of sentences from each of the three conditions. Each list also contained 68 filler sentences.

\section{Procedure}

Participants' eye movements were recorded with an EyeLink 1000 system at a sampling rate of $1,000 \mathrm{~Hz}$, which was calibrated at the beginning of each session and recalibrated throughout the session as needed. A chinrest was used to minimize head movement. Participants were instructed to read each sentence at a natural pace. At the start of each trial, a fixation point was presented near the left edge of the monitor, marking the location where the first word of the sentence would appear. When the participant's gaze was steady on this point, the experimenter presented the sentence. Participants pressed a button on a handheld console when they had finished reading the sentence, which made the sentence disappear and a true-false comprehension question appear in its place. Participants pressed one button to answer "true," and another button to answer "false." Mean comprehension accuracy was $97 \%$.

Participants were first presented with four of the filler sentences. After this warm-up block, the remaining 100 sentences were presented in a different random order for each participant.

\section{Analysis}

Data analysis focused on five standard eye-movement measures that reflect a range of processing stages (Clifton, Staub, \& Rayner, 2007; Rayner, 1998). First-fixation duration is the average of the durations of the initial, first-pass fixation on a word, regardless of the total number of first-pass fixations. Gaze duration is the average of the sum of all first-pass fixations on a word. These two measures are thought to reflect the earliest stages of word recognition, including processes of perceptual encoding and lexical access. First-pass regression rate is the proportion of trials on which a first-pass fixation on a word is followed by a regressive saccade rather than a progressive saccade. Regression-path duration is the sum of all fixations beginning with the initial fixation on a word and ending when gaze is directed away from the region to the right. Thus, regression-path duration includes time spent rereading earlier parts of the sentence before the reader is ready to proceed with the rest of the sentence. First-pass regression rate and regression-path duration are thought to reflect processes involved in integrating a word with earlier parts of the sentence. Rereading duration is the sum of all fixations on a 
word that are not included in gaze duration. Unlike the other measures, rereading duration includes zeroes (i.e., trials where the word was not refixated after first-pass reading). This measure is thought to reflect later stages of processing, including any lingering difficulty associated with integrating the word with the rest of the sentence.

An automatic procedure in the EyeLink software combined fixations that were shorter than $80 \mathrm{~ms}$ and within one character of another fixation into one fixation. Additional fixations shorter than $80 \mathrm{~ms}$ and longer than $800 \mathrm{~ms}$ were eliminated. In addition, means and standard deviations were computed separately for each dependent measure within each condition. Reading times that were greater than three standard deviations from the condition mean were eliminated. This procedure affected $1.7 \%$ of the data.

\section{Results}

Mean reading times for the target word (e.g., memo) are presented in Table 1. To assess whether reading times were systematically affected by increases or decreases in linguistic focus, we analyzed the data using linear trend analyses. We also report pairwise contrasts for the three conditions. For first-fixation duration, the effect of linguistic focus was marginally significant only in the subject analysis, $F_{1}(1,38)=$ $3.94, p<.06, F_{2}<1$. In contrast, the effect of linguistic focus was fully significant in analysis of both gaze duration, $F_{1}(1$, $38)=7.28, p<0.02, F_{2}(1,35)=4.16, p<0.05$ (Focused vs. Neutral: $t_{1}(38)=1.20, p>0.05 ; t_{2}(35)=1.17, p>0.05$; Neutral vs. Defocused: $t_{1}(38)=1.50, p>0.05 ; t_{2}(35)=$ 1.16, $p>0.05$; Focused vs. Defocused: $t_{1}(38)=2.70, p<$ $\left.0.02 ; t_{2}(35)=2.04, p<0.05\right)$, and regression-path duration, $F_{1}(1,38)=5.77, p<0.03, F_{2}(1,35)=6.47, p<0.02$ (Focused vs. Neutral: $t \mathrm{~s}<1$; Neutral vs. Defocused: $t_{1}(38)=1.94, p<$ $0.10 ; t_{2}(35)=1.13, p>0.05$; Focused vs. Defocused: $t_{1}(38)=$ $\left.2.40, p<0.03 ; t_{2}(35)=2.054, p<0.02\right)$, such that reading times became longer as the syntactic structure of the sentence made the target word increasingly more focused. ${ }^{1}$ In addition, the effect of linguistic focus was marginally significant in analysis of first-pass regression rate, $F_{1}(1,38)=3.27, p<$

\footnotetext{
${ }^{1}$ Given the marginally significant effects of focus on firstfixation duration and the fully significant effects on gaze duration, we were interested in whether focus was also associated with an increased likelihood of refixation during first-pass reading. Analysis of number of first-pass fixations showed a numeric pattern consistent with this idea (Focused $=1.15$, Neutral $=1.13$, Defocused $=1.11)$; however, the linear trend analysis was not significant, $F_{1}(1,38)=2.31, p>0.10 ; F_{2}(1$, $35)=2.07, p>0.10)$.
}

$0.10, F_{2}(1,35)=3.50, p<0.10$ (Focused vs. Neutral: $t \mathrm{~s}<1$; Neutral vs. Defocused: $t_{1}(38)=1.79, p<0.10 ; t_{2}(35)=1.12, p$ $>0.05$; Focused vs. Defocused: $t_{1}(38)=1.81, p<0.10 ; t_{2}(35)$ $=1.87, p<0.10)$, such that regression rates were higher as the target word became increasingly more focused. The effect of linguistic focus was not significant in the analysis of rereading duration $F_{\mathrm{S}}<1$.

To ensure that the reading-time patterns we observed on the target noun were not due to spillover effects associated with processing the verb, we analyzed reading times on the determiner-adjective region immediately preceding the target noun. Any spillover effects from processing the verb should manifest as effects in first-fixation duration and/or gaze duration on the determiner-adjective region, as spillover effects from an earlier region typically emerge in measures of initial reading on a later region (e.g., Rayner \& Duffy, 1986).

Mean reading times for the determiner-adjective region (e.g., the official) are presented in Table 2. Linear trend analyses showed no significant effects for first-fixation duration or gaze duration, suggesting that any difficulty associated with processing the verb did not spill over onto this region. However, analysis of first-pass regression rates showed a significant effect, $F_{1}(1,38)=16.91, p<0.001, F_{2}(1,35)=21.94, p<$ 0.001 , with regression rates for the Focused condition significantly higher than both the Neutral condition, $t_{1}(38)=5.17, p$ $<0.001 ; t_{2}(35)=4.97, p<0.001$, and the Defocused condition, $t_{1}(38)=4.11, p<0.001 ; t_{2}(35)=4.68, p<0.001$. A similar pattern was observed for the regression-path duration data but was only marginally significant, $F_{1}(1,38)=4.04, p<$ $0.06, F_{2}(1,35)=3.10, p<0.10$. Closer examination of these patterns revealed that the high rates of regressions and marginally longer regression-path durations in the Focused condition compared with the other two conditions were due in large part to differences in skipping rates of the previous word. Specifically, the word immediately preceding this region in the Focused condition was always the word was, which was skipped on $42 \%$ of trials, whereas the word immediately preceding this region in the other two conditions was always a longer, less-frequent verb (e.g., typed), which was skipped on $14 \%$ of trials. Previous work has demonstrated that inflated skipping rates for short, frequent words often are due to oculomotor targeting errors, which are corrected with an immediate regression (e.g., Drieghe, Rayner, \& Pollatsek, 2005).

More interestingly, analysis of rereading duration on the determiner-adjective region showed a significant effect, $F_{1}(1,38)=11.48, p<0.005, F_{2}(1,35)=15.18, p<0.001$, such that rereading duration on this region increased as the target word became increasingly more focused. This pattern of rereading durations on the determiner-adjective region directly complements the pattern of regression-path durations on the target noun. That is, a syntactically focused target word promotes longer reading times on the word itself, as well as more time regressing to the words that came immediately before it, 
Table 1 Mean reading-time results (standard errors in parentheses) for the target word across focus conditions

\begin{tabular}{llllll}
\hline Condition & First-fixation duration & Gaze duration & First-pass regression rate & Regression-path duration & Rereading duration \\
\hline Focused & $224(6)$ & $250(8)$ & $0.15(0.02)$ & $305(11)$ & $103(11)$ \\
Neutral & $222(7)$ & $243(9)$ & $0.13(0.02)$ & $293(12)$ & $112(13)$ \\
Defocused & $217(6)$ & $234(7)$ & $0.10(0.02)$ & $274(12)$ & $108(18)$ \\
\hline
\end{tabular}

First-pass regression rates are presented as proportions. Other measures are in milliseconds

perhaps reflecting processing associated with deeper integration of the focused target word with its preceding context.

\section{Discussion}

The current experiment manipulated whether a target word was syntactically defocused, neutral, or focused. Results showed that reading times systematically increased as the word became increasingly more focused. Although there was some evidence for this effect in first-fixation duration, the pattern was strongest for gaze duration and regressionpath duration on the target word, as well as rereading of the words that came immediately before the target word. These findings are consistent with the notion that linguistic focus promotes deeper encoding and integration of a word during sentence processing.

These results are consistent with previous demonstrations showing that increased linguistic focus is associated with longer reading times (Benatar \& Clifton, 2014; Birch \& Rayner, 1997; Price \& Sanford, 2012). These results also are consistent with our own previous work investigating effects of sentence structure on processing of complex semantic constructions (Lowder \& Gordon, 2012, 2013, 2015a, b), where we have shown that readers experience reduced processing difficulty for words that are embedded inside a relative clause or other defocused adjunct phrase compared to when they are presented in a simple sentence. The current results are inconsistent with previous work showing that increased linguistic focus is associated with shorter reading times (Birch \& Rayner, 2010; Morris \& Folk, 1998) or has no effect on reading times (Ward \& Sturt, 2007). We suggest two methodological explanations for the inconsistencies found in this domain. First, as also noted by Birch and Rayner (2010), it is important to include a neutral baseline condition in addition to manipulations of focus and defocus. Without this condition, it is difficult to determine whether any observed differences are due to the presence of a focusing device, the presence of a defocusing device, or both. Previous work (e.g., Birch \& Rayner, 1997, 2010; Morris \& Folk, 1998; Ward \& Sturt, 2007) has tended to compare only two of these conditions (e.g., focused vs. defocused, or focused vs. neutral), without considering a range of focus conditions. Second, and perhaps more importantly, previous work has not adequately controlled for possible oculomotor differences between conditions. Controlling for these differences when manipulating syntax can be difficult; however, if a target word is immediately preceded by different words across conditions, or if its position in the line differs across conditions, then any readingtime differences that emerge may be due to systematic oculomotor differences rather than manipulations of linguistic focus. In the current experiment, the target word appeared in the same line position across conditions and always had the same words immediately before and after it across conditions, thus making it unlikely that the effects we obtained are due to oculomotor differences. We recommend that future experiments on linguistic focus adopt similar practices.

Although linear trend analyses revealed significant effects of focus in several reading-time measures, it should be noted that the adjacent pairwise comparisons (i.e., Focused vs. Neutral; Neutral vs. Defocused) were either marginally significant or not significant. This shows that it is important to examine a range of focus manipulations, as it seems to suggest that the degree of focus rather than absolute focus or absolute defocus relative to neutral is the critical factor.

We agree with Benatar and Clifton's (2014) assessment that linguistic focus is a broad, multifaceted construct, and that the cognitive mechanisms underlying the online processing of linguistic focus may differ, depending on the particular type of manipulation. Whatever the precise nature of these

Table 2 Mean reading-time results (standard errors in parentheses) for the determiner-adjective region across focus conditions

\begin{tabular}{llllll}
\hline Condition & First-fixation duration & Gaze duration & First-pass regression rate & Regression-path duration & Rereading duration \\
\hline Focused & $215(5)$ & $320(12)$ & $0.24(0.03)$ & $443(23)$ & $217(22)$ \\
Neutral & $230(6)$ & $355(13)$ & $0.10(0.02)$ & $409(17)$ & $184(31)$ \\
Defocused & $222(5)$ & $343(17)$ & $0.12(0.02)$ & $406(20)$ & $156(23)$ \\
\hline
\end{tabular}

First-pass regression rates are presented as proportions. Other measures are in milliseconds 
mechanisms, we have demonstrated that the online processing patterns for syntactically focused information are similar to the online patterns for contextually focused information such that increases in linguistic focus are associated with increases in reading time. With regard to syntax in particular, we propose that the structure of a sentence acts as a powerful linguistic cue to readers, indicating which constituents are more important to focus on than others. We believe that the longer times on linguistically focused information reflect deeper encoding, which explains why memory tends to be better for focused versus defocused information.

Authors Note This research was supported by R01 HD060440-06A2 from NICHD. We thank Kristine Chen for assistance in conducting the experiment.

\section{References}

Almor, A. (1999). Noun-phrase anaphora and focus: The informational load hypothesis. Psychological Review, 106, 748-765.

Baker, L., \& Wagner, J. L. (1987). Evaluating information for truthfulness: The effects of logical subordination. Memory \& Cognition, 15, 247-255.

Benatar, A., \& Clifton, C., Jr. (2014). Newness, givenness and discourse updating: Evidence from eye movements. Journal of Memory and Language, 71, 1-16.

Birch, S. L., Albrecht, J. E., \& Myers, J. L. (2000). Syntactic focusing structures influence discourse processing. Discourse Processes, 30, 285-304.

Birch, S. L., \& Garnsey, S. M. (1995). The effect of focus on memory for words in sentences. Journal of Memory and Language, 34, 232267.

Birch, S., \& Rayner, K. (1997). Linguistic focus affects eye movements during reading. Memory \& Cognition, 25, 653-660.

Birch, S., \& Rayner, K. (2010). Effects of syntactic prominence on eye movements during reading. Memory \& Cognition, 38, 740-752.

Bredart, S., \& Modolo, K. (1988). Moses strikes again: Focalization effect on a semantic illusion. Acta Psychologica, 67, 135-144.

Carpenter, P. A., \& Just, M. A. (1977). Integrative processes in comprehension. In D. LaBerge \& S. J. Samuels (Eds.), Basic processes in reading: Perception and comprehension (pp. 217-241). Hillsdale, NJ: Erlbaum.

Clifton, C., Jr., Staub, A., \& Rayner, K. (2007). Eye movements in reading words and sentences. In R. P. G. van Gompel, M. H. Fischer, W. S. Murray, \& R. L. Hill (Eds.), Eye movements: A window on mind and brain (pp. 341-371). Amsterdam, the Netherlands: Elsevier.

Cutler, A., \& Fodor, J. A. (1979). Semantic focus and sentence comprehension. Cognition, 7, 49-59.

Drieghe, D., Rayner, K., \& Pollatsek, A. (2005). Eye movements and word skipping during reading revisited. Journal of Experimental Psychology: Human Perception and Performance, 31, 954-969.

Ferreira, F., \& Henderson, J. M. (1993). Reading processes during syntactic analysis and reanalysis. Canadian Journal of Experimental Psychology, 47, 247-275.

Foraker, S., \& McElree, B. (2007). The role of prominence in pronoun resolution: Active versus passive representations. Journal of Memory and Language, 56, 357-383.
Gergely, G. (1992). Focus-based inferences in sentence comprehension. In I. A. Sag \& A. Szabolcsi (Eds.), Lexical matters (pp. 209-240). Stanford, CA: Center for the Study of Language and Information.

Gernsbacher, M. A., \& Jescheniak, J. D. (1995). Cataphoric devices in spoken discourse. Cognitive Psychology, 29, 24-58.

Gordon, P. C., \& Hendrick, R. (1997). Intuitive knowledge of linguistic co-reference. Cognition, 62, 325-370.

Gordon, P. C., \& Hendrick, R. (1998). The representation and processing of coreference in discourse. Cognitive Science, 22, 389-424.

Gordon, P. C., \& Scearce, K. A. (1995). Pronominalization and discourse coherence, discourse structure, and pronoun interpretation. Memory \& Cognition, 23, 313-323.

Halliday, M. A. K. (1967). Notes on transitivity and theme in English: Part 2. Journal of Linguistics, 3, 199-244.

Hornby, P. A. (1974). Surface structure and presupposition. Journal of Verbal Learning and Verbal Behavior, 13, 530-538.

Klin, C. M., Weingartner, K. M., Guzman, A. E., \& Levine, W. H. (2004). Readers' sensitivity to linguistic cues in narratives: How salience influences anaphor resolution. Memory \& Cognition, 32, 511-522.

Langford, J., \& Holmes, V. M. (1979). Syntactic presupposition in sentence comprehension. Cognition, 7, 363-383.

Lowder, M. W., \& Gordon, P. C. (2012). The pistol that injured the cowboy: Difficulty with inanimate subject-verb integration is reduced by structural separation. Journal of Memory and Language, 66, 819-832.

Lowder, M. W., \& Gordon, P. C. (2013). It's hard to offend the college: Effects of sentence structure on figurative-language processing. Journal of Experimental Psychology: Learning, Memory, \& Cognition, 39, 993-1011.

Lowder, M. W., \& Gordon, P. C. (2015a). Natural forces as agents: Reconceptualizing the animate-inanimate distinction. Cognition, 136, 85-90.

Lowder, M. W., \& Gordon, P. C. (2015b). The manuscript that we finished: Structural separation reduces the cost of complement coercion. Journal of Experimental Psychology: Learning, Memory, \& Cognition, 41, 526-540.

McKoon, G., Ratcliff, R., Ward, G., \& Sproat, R. (1993a). Syntactic prominence effects on discourse processes. Journal of Memory and Language, 32, 593-607.

McKoon, G., Ward, G., Ratcliff, R., \& Sproat, R. (1993b). Morphosyntactic and pragmatic factors affecting the accessibility of discourse entities. Journal of Memory and Language, 32, 56-75.

Moravcsik, J. E., \& Healy, A. F. (1998). Effect of syntactic role and syntactic prominence on letter detection. Psychonomic Bulletin \& Review, 5, 96-100.

Morris, R. K., \& Folk, J. R. (1998). Focus as a contextual priming mechanism in reading. Memory \& Cognition, 26, 1313-1322.

Price, J. M., \& Sanford, A. J. (2012). Reading in healthy ageing: The influence of information structuring in sentences. Psychology and Aging, 27, 529-540.

Rayner, K. (1998). Eye movements in reading and information processing: 20 years of research. Psychological Bulletin, 124, 372-422.

Rayner, K., \& Duffy, S. A. (1986). Lexical complexity and fixation times in reading: Effects of word frequency, verb complexity, and lexical ambiguity. Memory \& Cognition, 14, 191-201.

Singer, M. (1976). Thematic structure and the integration of linguistic information. Journal of Verbal Learning and Verbal Behavior, 15, 549-558.

Sturt, P., Sanford, A. J., Stewart, A., \& Dawydiak, E. (2004). Linguistic focus and good-enough representations: An application of the change-detection paradigm. Psychonomic Bulletin \& Review, 11, 882-888.

Ward, P., \& Sturt, P. (2007). Linguistic focus and memory: An eye movement study. Memory \& Cognition, 35, 73-86. 